\title{
Effect of Occupational Therapy Intervention Inpost-operative Mandibular Fractures - A Retrospective Study
}

\author{
Vaijanti Jain*, Arti Yadav, Ashwini Chauhan \\ Occupational Therapist, Seth GS Medical College and KEM Hospital, Mumbai, India \\ Email address: \\ vijujain_23@yahoo.com (V. Jain) \\ ${ }^{*}$ Corresponding author
}

\section{To cite this article:}

Vaijanti Jain, Arti Yadav, Ashwini Chauhan. Effect of Occupational Therapy Intervention Inpost-operative Mandibular Fractures - A Retrospective Study. Clinical Medicine Research. Vol. 10, No. 2, 2021, pp. 53-58. doi: 10.11648/j.cmr.20211002.14

Received: March 29, 2021; Accepted: April 14, 2021; Published: April 26, 2021

\begin{abstract}
Aim: To find the effectiveness of Occupational therapy intervention in post operative mandibular fracture patients. Objective: To improve mouth opening and reduce jaw deviations (temporomandibular joint mobility). Study design: A Retrospective study. Study setting: OPD of Occupational Therapy Department In Seth G. S. Medical College, KEM Hospital, Parel, Mumbai -400012, India. Methodology: Data was retrieved from Occupational therapy department records for the last one and half years i.e from july 2019 to jan 2021. In the said period around 33 operated mandibular fractures patients had been referred to Occupational therapy dept for therapy. Out of which only 20 patients followed up. Data of these 20 mandibular fractures patients were analysed. Inclusion criteria, Both males and females, Age group 20-60 years, Operated for mandibular fractures in period July 2019 - January 2021 who were referred to occupational therapy department for therapeutic intervention. Exclusion criteria: Incomplete data, Patients who have not followed up for second visit also. Outcome measures - Mouth opening with a tape measure at $1^{\text {st }}, 3^{\text {rd }}$ and $5^{\text {th }}$ week respectively. All these data was already available in Occupationa therapy department records and there was no patient contact at all. Hence waiver of consent was asked for. Results: Statistical analysis (paired t-test) was used to assess the significance of difference. The calculated $t$ value for mouth opening measurements was 17.1850 which was much much higher than the tabular $t$ value at $\mathrm{P}=0.001$, which means the increase in post treatment mouth opening measurements is just not by chance but it's extremely significant at $p=0.001$. The pre and post photograph of the patients showed a difference in jaw deviation angle too while opening mouth. The above results showed the treatment proved to be effective. Conclusion: The Occupation therapy intervention in post-operative mandibular fracture patients proved to be effective in improving mouth opening measurements and jaw deviations.
\end{abstract}

Keywords: Mandibular Fractures, Post Operative, Occupational Therpy, Mouth Opening, Jaw Deviations

\section{Introduction}

Mandibular fracture also known as jaw fracture, is a breach in the continuity of the mandibular bone. According to a study done in North India in 2018 consisting of 1015 individuals showed that the most common anatomic site for mandibular fracture is parasymphyseal region (40.3\%), followed by angle $(28.8 \%)$, condyle $(27.6 \%)$ andsymphysis $(12.5 \%)$ of mandible. The coronoid process of mandible $(4.3 \%)$ was least involved in mandibular fracture. Males $(30.8 \%)$ were more prone to mandibular fractures than females $(15.7 \%)$ [1, 2]. The commonest etiology for mandibular fractures is trauma followed by some rare etiologies like osteonecrosis or tumor. The symptoms frequently described by patients following mandibular fractures are pain and the feeling that teeth no longer correctly meet (traumatic malocclusion or disocclusion). Other symptoms may include loose teeth, numbness and trismus [3]. Signs which can be noticed outside the mouth are swelling, bruising and deformity. Management of mandibular fracture can be conservative or operative (open or closed reduction with internal fixation). External fixation can be 
used in cases of comminuted mandibular fractures. Complications observed post operatively are jaw deviations, reduced mouth opening, malunion, nonunion, difficulties in chewing, biting [3, 4]. Post operative occupational therapy rehabilitation focuses on oral hygiene, dietary advices, mouth ranges and jaw movements.

\section{Aim}

To find the effectiveness of Occupational Therapy intervention in postoperative mandibular fractures patients.

\section{Objective}

To improve mouth opening and reduce jaw deviations (temporomandibular joint mobility).

\section{Review of Literature}

National journal of maxillo facial surgery 2018 jul-dec; 9 (2): 123-128. Akhilanand Chaurasia and Gaurav Katheriya conducted a study on prevalence of mandibular fracture in patients visiting a tertiary dental care hospital in North India. concluded that epidemiological review are essential to identify risk factors leading to mandibular fracture. The success of treatment and the implementation of preventive measure is more reliant on the epidemiological assessments.

A retrospective crossectional study of maxillofacial trauma in delhi NCR region, journal of family medicine and primary care, 2019 vol 8, issue 4: 1453-1459 lokesh Chandra and et al. concluded that physical assault is the leading cause of maxillo facial trauma. the commonest facial fracture was isolated mandibular fracture. Preventive measures by enforcing strict traffic rules along with improvement in education and socio economic status would help to avoid maxillo facial injuries.

Annals Of Maxillofacial Surgery 2019 June, vol 9 (124-128) Bhuvaneshwari Srinivasan, Ramdas Balakrishnan, $\mathrm{H}$ Sudarshan, GC Veena, Suhas Prabhakar conducted a study on retrospective analysis of 162 mandibular fractures: an institutional experience and concluded that surveys play a vital role in better understanding the biomechanics of mandible fractures. Futhermore, analysis of the treatment modalities used and their respective outcomes are of paramount importance in guiding surgeons to evaluate their efficacy.

Medicina April 2019, (TanjaBoljevic, Batric Vukcevic, Zoran Pesic, And Aleksandar Boljevic) conducted a study on the quality of life of patients with surgically treated mandibular fractures and the relationship of the post traumatic pain and trismus with the postoperative complications: A Prospective Study that showed a significantly lower quality of life regarding appearance, swallowing and anxiety. Given the fact that the modern lifestyle is associated with an increased risk of facial trauma, it is imperative to acknowledge the potential risk factors for postoperative complications. Additionally, this study should inspire clinicians to provide psychological support to the patients in order to achieve a superior therapeutic effect.

National journal of maxillofacial surgery, 5 (2), 153, 2014 conducted on prevalence and pattern of mandibular fractures in Central India. This study concluded that large number of mandibular fractures attributed to RTA's and incidence of maxillofacial Fractures can be significantly reduced by strict enforcement of traffic rules.

SADJ June 2015, vol 70 no 5 p196-p199 (A van der Merwe, R Barnes) conducted a study on the need for physiotherapy intervention for mandibular condyle fracture patients: a needs analysis and concluded that the study results confirmed that, according to expert opinion, adequate and prompt post -operative physiotherapeutic intervention for patients who sustained mandibular condyle fractures is important to achieve more favorable post-surgical results. The study provided a platform for expanding the evidence base for physiotherapy in maxilla-facial conditions.

Physical therapy in Tempromandibular dysfunction following maxilla- mandibular fixation in sub condylar mandibular fracture - A single case study done by Ratan Khuman et al Concluded that physical therapy intervention with an effective exercise program may be an effective strategy in a management of temporomandibular dysfunction following fractures. The patient showed improvement in mouth opening measurements following the therapy. IJHSR, VOL 3, issue: 9, sep. 2013.

Scientific reports (2018) 8: 7724, DOI: 10.1038, www.nature.com. Hai-hua zhou et al conducted a clinical retrospective case control study on the mechanics of obstacle in mouth opening and mal occlusion in patients with maxillofacial fractures revealed that patients associated with serious mouth opening limitation should prefer surgical procedure.

Kamulegeya A, Lakor F, Kabenge K. Oral maxillofacial fractures seen at a Ugandan tertiary hospital: A six-month prospective study. Clinics (Sao Paulo) 2009; 64: 843-8. [PMC free article] [PubMed] [Google Scholar] concluded that Anticipated changes in maxillofacial trauma trends necessitate regular epidemiologic studies of facial fractures to allow for development and implementation of timely novel preventive measures.

10. Al Ahmed HE, Jaber MA, Abu Fanas SH, Karas M. The pattern of maxillofacial fractures in Sharjah, United Arab Emirates: A review of 230 cases. Oral Surg Oral Med Oral Pathol Oral Radiol Endod. 2004; 98: 166-70. [PubMed] [Google Scholar] says that the causes and incidence of maxillofacial injuries vary from one country to another and, as such, can provide a guide to the design of programs geared toward prevention and treatment.

11. Chandra Shekar BR, Reddy C. A five-year retrospective statistical analysis of maxillofacial injuries in patients admitted and treated at two hospitals of Mysore city. Indian J Dent Res. 2008; 19: 304-8. [PubMed] [Google Scholar] concluded that RTAs are the most common cause for maxillofacial injuries. If RTAs are considered an epidemic of modern times, then prevention is its vaccine.

12. Qudah MA, Al-Khateeb T, Bataineh AB, Rawashdeh MA. Mandibular fractures in Jordanians: A comparative 
study between young and adult patients. J Craniomaxillofac Surg. 2005; 33: 103-6. [PubMed] they stated that The most common fracture site in adult patients was the mandibular body, whereas the condyle predominated in young patients. The most common causative factor in adults was road traffic accidents, and falls in the young.

13. Nagi R, Sahu S, Gahwai D, Jain S. Study on evaluation of normal range of maximum mouth opening among Indian adults using three finger index: A descriptive study. Journal of Indian Academy of Oral Medicine and Radiology. 2017 Jul 1; 29 (3): 186. This study suggested that three finger index is a convenient and reliable tool for assessing normal maximum mouth opening. It is a most appropriate method to distinguish normal from restricted mouth opening. Even in children MMO was found to correlate with body height and weight and was found to be simple method to assess MMO. In future, more studies on large sample sizes should be encouraged and studies should be focused on TMJ disorders and other pathologic conditions that influence mouth opening

\section{Methodology}

Data was retrieved from Occupational therapy department records for the last one and half years i.e from July 2019 to Jan 2021. In the said period around 33 operated mandibular fractures patients had been referred to Occupational therapy department for therapy. Out of total 33 patients referred to occupational therapy department only 20 patients continued with the therapeutic intervention and remaining 13 patients just came for the first time and never followed up later on.

Patients were evaluated on day 1 by measuring the distance of mouth opening between upper and lower teeth using a measuring tape. Follow up assessments were done on $3^{\text {rd }}$ and $5^{\text {th }}$ week respectively.

Patients were given following exercises:

Ice cream stick exercises (gradual increment in no. of stick.) [figure 1]

Mouth opening exercises.

Side to side jaw movements.

Mouth blowing and puffing exercises.

Lips smacking exercises.

Each of these above mentioned exercises were advised to be done every two hourly i.e at least 5 times a day, with 10 repetitions of each set. For ice-cream sticks exercises patients were made to hold sticks for 10-15 seconds and repeat it for 10 times. In ice-cream stick exercises patients were initially given a number of sticks as assessed by the therapist, depending on patients mouth opening, and then gradually patients were asked to increase sticks as range improves. Blowing exercises were explained in forms of paper blowing and candle blowing. Lip smacking exercises patients were advised to take both their lips inside their mouth (pursed lips) and hold them for 5 seconds. For jaw deviations exercises patients were explained by visual demonstration to move jaw in both direction in front of mirror. The same exercises were given as home program and family members were instructed to supervise the same.

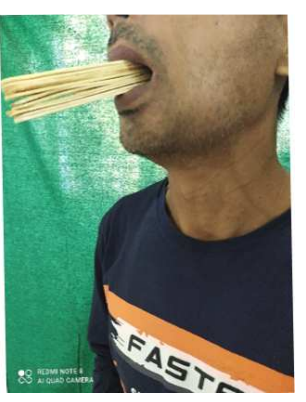

Figure 1. Ice cream stick exercises.

\section{Inclusion criteria}

1. Both males and females

2. Age group 20-60 years

3. Operated for mandibular fractures in period July 2019 January 2021 who were referred to Occupational therapy department for therapeutic intervention.

\section{Exclusion criteria:}

Incomplete data

Patients who have not followed up for second visit also.

\section{Results}

The paired t-test was used to compare the pre and post test difference in mouth opening measurements in post-operative mandibular fracture patients. The mean of differences came out to be 3.26 and SD for above values was 0.8481 .

The calculated $t$ value for mouth opening measurements was 17.1850 which was much much higher than the tabular $\mathrm{t}$ value at $\mathrm{P}=0.001$, which means the increase in post treatment mouth opening measurements is just not by chance but it's extremely significant at $\mathrm{p}=0.001$. The pre and post photograph of the patients showed a difference in jaw deviation angle too while opening mouth [figures 2, 3]. The above results showed the treatment proved to be effective.

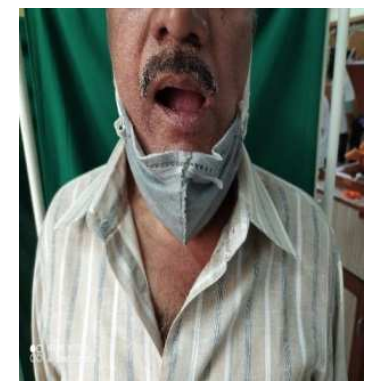

Figure 2. Jaw deviations Pre Therapy..

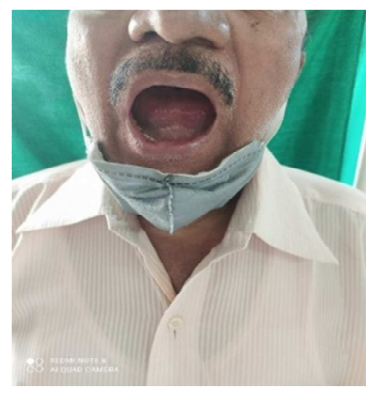

Figure 3. Jaw deviation Post Therapy. 
Table 1. Demographics and mouth opening ranges of patients.

\begin{tabular}{|c|c|c|c|c|c|c|}
\hline $\begin{array}{l}\text { No. of } \\
\text { subject }\end{array}$ & Age/sex & Diagnosis & $\begin{array}{l}\text { Date of } \\
\text { surgery }\end{array}$ & $\begin{array}{l}\text { Initial mouth } \\
\text { opening }\left(1^{\text {st }}\right. \\
\text { week })\end{array}$ & $\begin{array}{l}\text { Post } \\
\text { operative } \\
\left(3^{\text {rd }} \text { week }\right)\end{array}$ & $\begin{array}{l}\text { Final mouth } \\
\text { opening }\left(5^{\text {th }}\right. \\
\text { week })\end{array}$ \\
\hline 1 & $43 /$ male & $\mathrm{b} / \mathrm{L}$ high condylar fracture & $18 / 12 / 20$ & $1.5 \mathrm{~cm}$ & $3.2 \mathrm{~cm}$ & $5 \mathrm{~cm}$ \\
\hline 2 & $21 /$ male & Rt. And lt. angle of mandible & $19 / 11 / 20$ & $1.5 \mathrm{~cm}$ & $3.5 \mathrm{~cm}$ & $7 \mathrm{~cm}$ \\
\hline 3 & $21 \mathrm{y} /$ female & Fracture of both condylar process of rt. Mandible fracture & $6 / 11 / 20$ & $2.5 \mathrm{~cm}$ & $4.5 \mathrm{~cm}$ & $5.0 \mathrm{~cm}$ \\
\hline 4 & $21 /$ female & Fracture of mandible angle and rt. PS mandible fracture & $25 / 11 / 20$ & $2 \mathrm{~cm}$ & $3.6 \mathrm{~cm}$ & $4.5 \mathrm{~cm}$ \\
\hline 5 & $43 /$ male & Rt. Angle and Lt. mandible fracture & $16 / 10 / 20$ & $2.0 \mathrm{~cm}$ & $3.5 \mathrm{~cm}$ & $5.3 \mathrm{~cm}$ \\
\hline 6 & 48/male & Bicondylar Mandibular fracture & $27 / 12 / 19$ & $1.5 \mathrm{~cm}$ & $2.7 \mathrm{~cm}$ & $4.8 \mathrm{~cm}$ \\
\hline 7 & $20 \mathrm{y} / \mathrm{male}$ & Lt. Angle and rt. PS mandibilar fracture & $31 / 1 / 2020$ & $2.0 \mathrm{~cm}$ & $3.3 \mathrm{~cm}$ & $5.0 \mathrm{~cm}$ \\
\hline 8 & $50 \mathrm{y} / \mathrm{male}$ & Lt angle mandibular fracture & $17 / 11 / 2020$ & $2.0 \mathrm{~cm}$ & $4.0 \mathrm{~cm}$ & $7.0 \mathrm{~cm}$ \\
\hline 9 & $42 \mathrm{y} / \mathrm{male}$ & Rt. Angle Mandibular fracture & $3 / 2 / 2020$ & $1.5 \mathrm{~cm}$ & $3.2 \mathrm{~cm}$ & $4.5 \mathrm{~cm}$ \\
\hline 10 & $40 y$ female & bicondylar Mandibular fracture & $14 / 10 / 2020$ & $2.0 \mathrm{~cm}$ & $3.0 \mathrm{~cm}$ & $4.5 \mathrm{~cm}$ \\
\hline 11 & $21 \mathrm{y} / \mathrm{male}$ & Rt. Mandibular body and angle fracture & $20 / 7 / 2020$ & $2.4 \mathrm{~cm}$ & $4.4 \mathrm{~cm}$ & $5.2 \mathrm{~cm}$ \\
\hline 12 & $43 \mathrm{y} / \mathrm{male}$ & bicondylar mandibular fracture & $4 / 1 / 2019$ & $2.6 \mathrm{~cm}$ & $4.3 \mathrm{~cm}$ & $6.0 \mathrm{~cm}$ \\
\hline 13 & $30 y /$ female & Lt PS Mandibular and rt. anglefracture & $10 / 6 / 2019$ & $1.6 \mathrm{~cm}$ & $2.4 \mathrm{~cm}$ & $4.2 \mathrm{~cm}$ \\
\hline 14 & $40 \mathrm{y} / \mathrm{male}$ & Lt. PS Mandibular fracture & $8 / 6 / 2019$ & $2.4 \mathrm{~cm}$ & $4.0 \mathrm{~cm}$ & $6.5 \mathrm{~cm}$ \\
\hline 15 & $21 \mathrm{y} / \mathrm{male}$ & Rt ramus mandibular fracture & $17 / 10 / 2020$ & $0.6 \mathrm{~cm}$ & $1.8 \mathrm{~cm}$ & $3.2 \mathrm{~cm}$ \\
\hline 16 & $32 \mathrm{y} / \mathrm{male}$ & PS Mandibular fracture & $3 / 2 / 2020$ & $1.5 \mathrm{~cm}$ & $3.2 \mathrm{~cm}$ & $5.0 \mathrm{~cm}$ \\
\hline 17 & $30 \mathrm{y} / \mathrm{male}$ & left PS mandibular fracture & $26 / 6 / 2020$ & $1.6 \mathrm{~cm}$ & $2.4 \mathrm{~cm}$ & $3.6 \mathrm{~cm}$ \\
\hline 18 & $26 \mathrm{y} / \mathrm{male}$ & Lt. angle and mandible & $17 / 1 / 2019$ & $2.5 \mathrm{~cm}$ & $3.7 \mathrm{~cm}$ & $6 \mathrm{~cm}$ \\
\hline 19 & $38 \mathrm{y} / \mathrm{male}$ & Lt. PS mandibular fracture & $17 / 7 / 2018$ & $1.2 \mathrm{~cm}$ & $2.8 \mathrm{~cm}$ & $4.8 \mathrm{~cm}$ \\
\hline 20 & $28 \mathrm{y} / \mathrm{male}$ & mandible parasymphysis fracture & $3 / 3 / 2018$ & $1.5 \mathrm{~cm}$ & $3 \mathrm{~cm}$ & $4.5 \mathrm{~cm}$ \\
\hline
\end{tabular}

\section{Mean mouth opening ranges pre and post therapy}

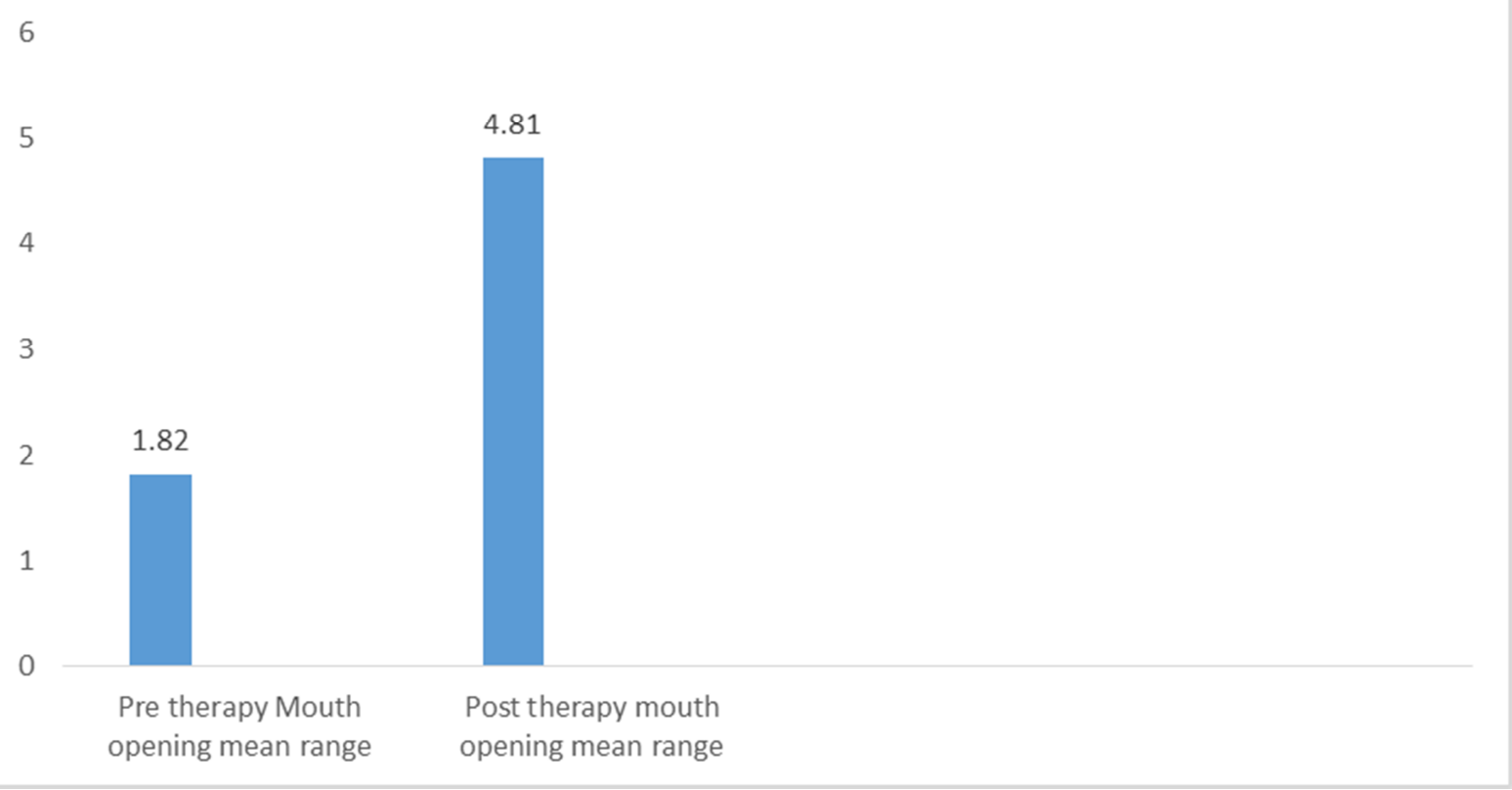

Figure 4. Mean mouth opening range table. X axis depicts the pre and post therapy mouth opening ranges and $Y$ axis depicts range in cms.

\section{Discussion}

Mandibular fracture is one of the commonest facial fracture and trauma is one of the commonest cause for it [1, 2, 5]. Complications observed post operatively are jaw deviations, reduced mouth opening, malunion, nonunion, difficulties in chewing, biting and traumatic mal occlusion and dis occlusion. [3, 4]. The mandibular fracture has more tendency to affect mouth opening ranges than most of the midfacial fracture except for the coronoid process fractures.
The fracture of condylar process results in severe limitations in mouth opening ranges. Condylar fractures destroy the integrity of the mandible and the muscle tension of the articular disk and lateral pterygoid cannot perform the function of mandibular movement consequently gliding movements, protrusion and lateral movement of mandible are weakened [8]. Therapeutic intervention has proven to be beneficial in reducing the above complications [6]. But there are very few studies and hardly any randomized control trials on post operative rehabilitation in mandibular fractures [15]. Mouth opening, blowing, jaw deviation, Mouth blowing and 
puffing exercises, Lips smacking exercises has proved beneficial in improving mouth opening $[1,16]$. Therapeutic intervention has proven to be beneficial in reducing the above complications [6]. Active mobilization exercises as mentioned above helps in early healing of fracture site with good functional ranges in mouth opening and jaw deviations [6-8]. The proportion of males affected due to mandibular fractures was higher than females in the study i.e. 4:1 [1]. Studies done by kamulegeya et al, ahmed et al, lilies et al and kuda et al concluded that male predominance was higher in mandibular fractures. Higher prevalence in males was due to their more frequent participation in high risk activities such as driving, sports that involve physical contact, an active social life and drug and alcohol habits whereas on contrary females were more housework and they drove vehicles less frequently and carefully, hence less exposed to accident, fights, industrial works and sports and less participated in trading. The maximum no. of patients in the study were found in the age group of 21-30 years (i.e. 11 patients), followed by 3 patients in the age group of 31-40 years and 6 patients in the age group of 41-50 years, which means most of the young patients had more incidences of mandibular fracture as compare to older population [13]. 80\% of the patients i.e 16 ptients in this study gave history of road traffic accident as cause of Fracture and $20 \%$ (i.e 4 patients) gave history of accidental falls [13]. The mean of difference noted in mouth opening ranges in 16 male patients of this study was $3.44 \mathrm{~cm}$ and in 4 female patients was $2.52 \mathrm{~cm}$ [14]. Out of the total 20 patients in the study who followed for the therapy maximum patients had fracture of para symphysis (6 patients) and angle of mandible (6 patients), next common fracture noted was condylar fracture (total 5) followed by two mixed fractures (i.e parasymphysis and angle) and least noted was ramus fracture (i.e 1 patient) [Figure 5] [9-12].

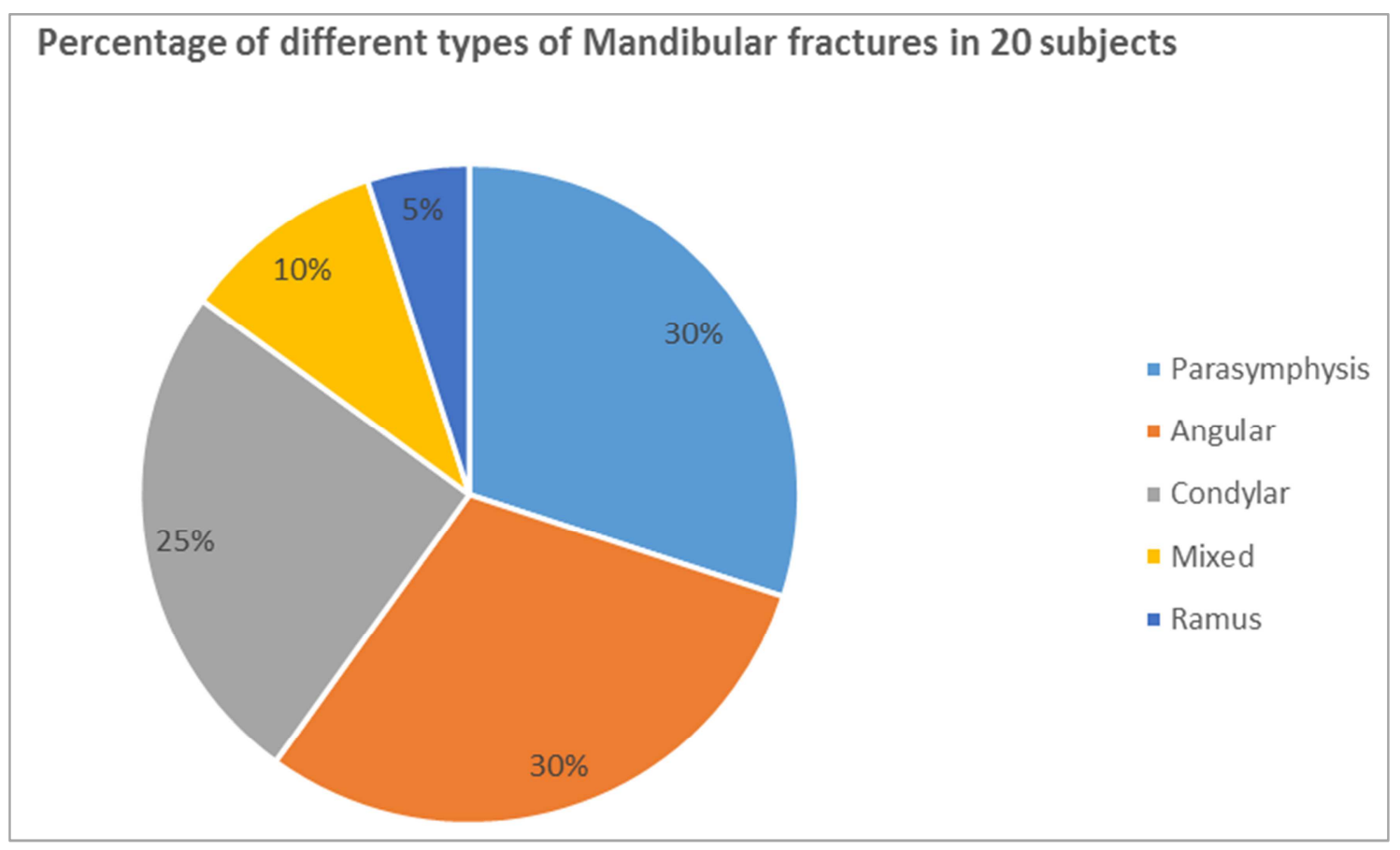

Figure 5. Pie chart showing percentages of types of mandibular fractures noted in 20 subjects during the study.

Occupational therapy intervention with active early mobilization protocol right from day 3 post surgery led to active healing of the fracture site and thus improving mouth opening ranges [table 1]. and reducing jaw deviations [figures $2,3]$. The above findings also gave a better facial appearance to the patients according to the therapist perspectives and as stated by the subjects themselves verbally.

\section{Conclusion}

The Occupation therapy intervention in post-operative mandibular fracture patients proved to be effective in improving mouth opening measurements and jaw deviations and thus improving facial appearance, according to patients perspective.

This study conducted at tertiary government hospital in a
Western metropolitan city of Mumbai even showed that prevalence of mandibular fractures was more in males and in the age group of 21-30 years. The commonest cause observed was road traffic accidents. The most common type of fractures were found to be parasymphysis and angle of mandible. The early therapeutic intervention in post operative mandibular fractures leads to better mouth ranges and improves jaw deviations.

\section{Limitation}

Small sample size. Out of total 33 patients referred to occupational therapy department only 20 patients continued with the therapeutic intervention, the remaining 13 patients just came for the first time and never followed up later on.

No objective assessments was used for jaw deviation. 


\section{Suggestions}

RCT should be done to prove the efficacy on large sample size

Functional outcome and quality of life could be assessed.

\section{Ethics}

Institutional Ethics Committee (IEC) - 2, Seth GS medical College and KEM Hospital, Mumbai, Maharashtra, India.

\section{Conflicts of Interest}

All the authors do not have any possible conflicts of interest.

\section{Acknowledgements}

Dr. Shilpshree palsule Asst. Prof, Occupational therapy dept, Seth G S medical college and Kem Hospital

Dr. Shifa Occupational therapy dept, Seth G S medical college and Kem Hospital

Dr Henna Occupational therapy dept, Seth G S medical college and Kem Hospital

Dr. Ankita Occupationaal therapy dept, Seth G S medical college and Kem Hospital

Dr Prachi Occupational therapy dept, Seth G S medical college and Kem Hospital

\section{References}

[1] Chaurasia A, Katheriya G. Prevalence of mandibular fracture in patients visiting a tertiary dental care hospital in North India. National journal of maxillofacial surgery. $2018 \mathrm{Jul} ; 9$ (2): 123.

[2] Chandra L, Deepa D, Atri M, Pandey SM, Passi D, Goyal J, Sharma A, Gupta U. A retrospective cross-sectional study of maxillofacial trauma in Delhi-NCR Region. Journal of family medicine and primary care. 2019 Apr; 8 (4): 1453.

[3] Srinivasan B, Balakrishna R, Sudarshan H, Veena GC, Prabhakar S. Retrospective analysis of 162 mandibular fractures: An institutional experience. Annals of maxillofacial surgery. 2019 Jan; 9 (1): 124.

[4] Boljevic T, Vukcevic B, Pesic Z, Boljevic A. The quality of life of patients with surgically treated mandibular fractures and the relationship of the posttraumatic pain and trismus with the postoperative complications: A prospective study. Medicina. 2019 Apr; 55 (4): 109.
[5] Dhananjay Barde, Anupama Mudhol, Ramnik Madan. National journal of maxillofacial surgery 5 (2), 153, 2014.

[6] Van der Merwe A, Barnes R. The need for physiotherapy intervention for mandibular condyle fracture patients: A needs analysis. South African Dental Journal. 2015 Jun; 70 (5): 196-9.

[7] Khuman R, Chavda D, Surbala L, Chaudhary E, Bhatt U, Nambi G. Physical therapy in temporomandibular dysfunction following maxillo-mandibular fixation in sub-condylar mandibular fracture-a single case study. Int J Health Sci Res. 2013; 3 (9): 45-55.

[8] Zhou HH, Lv K, Yang RT, Li Z, Yang XW, Li ZB. Clinical, retrospective case-control study on the mechanics of obstacle in mouth opening and malocclusion in patients with maxillofacial fractures. Scientific reports. 2018 May 16; 8 (1): $1-8$.

[9] Kamulegeya A, Lakor F, Kabenge K. Oral maxillofacial fractures seen at a Ugandan tertiary hospital: A six-month prospective study. Clinics (Sao Paulo) 2009; 64: 843-8. [PMC free article] [PubMed] [Google Scholar].

[10] Al Ahmed HE, Jaber MA, Abu Fanas SH, Karas M. The pattern of maxillofacial fractures in Sharjah, United Arab Emirates: A review of 230 cases. Oral Surg Oral Med Oral Pathol Oral RadiolEndod. 2004; 98: 166-70. [PubMed] [Google Scholar].

[11] ChandraShekar BR, Reddy C. A five-year retrospective statistical analysis of maxillofacial injuries in patients admitted and treated at two hospitals of Mysore city. Indian J Dent Res. 2008; 19: 304-8. [PubMed] [Google Scholar].

[12] Qudah MA, Al-Khateeb T, Bataineh AB, Rawashdeh MA. Mandibular fractures in Jordanians: A comparative study between young and adult patients. J Craniomaxillofac Surg. 2005; 33: 103-6. [PubMed].

[13] Arya Arun, Vivek Narayanan, C. Saravanan, Karthik R. Prevalence and the pattern of mandibular fractures in north east Chennai. International Journal of contemporary medical research 2020; 7 (8): H9-H12.

[14] Nagi R, Sahu S, Gahwai D, Jain S. Study on evaluation of normal range of maximum mouth opening among Indian adults using three finger index: A descriptive study. Journal of Indian Academy of Oral Medicine and Radiology. 2017 Jul 1; 29 (3): 186.

[15] Moraes AD, Sanches ML, Ribeiro EC, Guimarães AS. Therapeutic exercises for the control of temporomandibular disorders. Dental press journal of orthodontics. 2013 Oct; 18 (5): 134-9.

[16] Preventing trismus MSKCC.org, Memorial sloanKatering cancer center. 